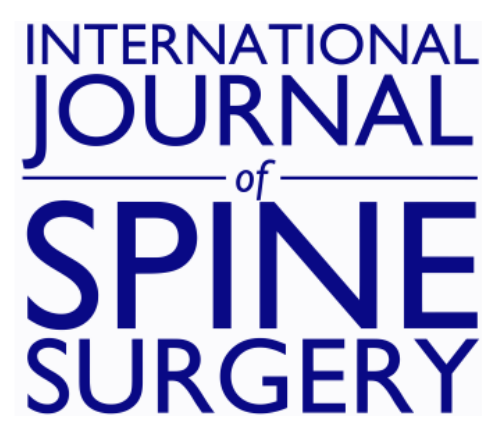

\title{
"Floating Cervical Spine Injuries": Craniocervical Dissociation with Associated, Noncontiguous, Unstable Cervical or Cervicothoracic Spine Fracture
}

Mario Taylor, Celeste Tavolaro, Carlo Bellabarba and Richard J. Bransford

Int J Spine Surg published online 22 September 2021

http://ijssurgery.com/content/early/2021/09/20/8111

This information is current as of April 26, 2023.

Email Alerts Receive free email-alerts when new articles cite this article. Sign up at: http://ijssurgery.com/alerts 


\title{
"Floating Cervical Spine Injuries": Craniocervical Dissociation with Associated, Noncontiguous, Unstable Cervical or Cervicothoracic Spine Fracture
}

\author{
MARIO TAYLOR, MD, CELESTE TAVOLARO, MD, CARLO BELLABARBA, MD, \\ RICHARD J. BRANSFORD, MD \\ Department of Orthopaedics and Sports Medicine, Harborview Medical Center, Seattle, Washington
}

\begin{abstract}
Background: Advances in prehospital life support of patients who have sustained high-energy trauma have resulted in an increase in the number of patients with craniocervical dissociations (CCDs) surviving. With better imaging and more severely injured patients surviving, we are now seeing other associated injuries. CCDs in association with unstable, noncontiguous, subaxial spine injuries have not been described. The objective of this study was to (1) describe this injury pattern and its characteristics, including the mechanism of injury, injury levels, and neurological deficits, and (2) understand prognosis and outcome.
\end{abstract}

Methods: After institutional review board approval, a retrospective study of patients who sustained CCD in association with an unstable, circumferential, subaxial, or cervicothroacic spine injury (C3-T2) between January 1, 2003, and August 31, 2018, was done. Review of imaging was performed to identify spine injury localization and type. Demographic data, mechanism of injury, neurological status, type of treatment, and patient outcomes were obtained from the electronic medical records.

Results: One hundred seventeen patients with CCD were identified, of which 105 had full spine radiographs. Thirteen (8 male and 5 female) had an associated, noncontiguous, unstable cervical, or cervicothoracic injury. Mean age was $45.4 \pm 19$ years. No exam could be obtained in 6; in the other 7, 1 was American Spinal Injury Association (ASIA) E, 1 ASIA D, and 5 ASIA A. Operative management of both injuries was planned for all 13 patients; however, 2 died before surgery. At discharge, there were 9 survivors with mean follow up of 2 years; 4 patients were independent ( 3 ASIA D, 1 ASIA E), and 5 were dependent (1 ASIA C, 4 ASIA A).

Conclusions: Approximately $12 \%$ of patients with $\mathrm{CCD}$ have a floating cervical spine injury. Floating cervical spine injuries have an unfavorable prognosis with $69 \%$ surviving to hospital discharge but only $31 \%$ functioning independently (ASIA D or E).

Level of Evidence: 4.

Clinical Relevance: Floating cervical spine injuries need to be recognized to optimize prognosis, yet even in the best of circumstances, prognosis is guarded.

Cervical Spine

Keywords: spinal cord injury, craniocervical dissociation, floating cervical spine, spine fracture, spine dislocation, subaxial dislocation

\section{INTRODUCTION}

Historically, craniocervical dissociations (CCDs) were generally fatal injuries, with patients rarely making it to a hospital alive. ${ }^{1}$ Advances in prehospital life support and early immobilization of patients who have sustained high-energy trauma have resulted in an increase in the number of patients with CCD reaching the hospital. ${ }^{1-3}$ Even after arrival to a medical facility, however, only about a quarter of patients ( 4 out of 17 or $24 \%$ ) ultimately were diagnosed with CCD in a timely manner, and with delay in diagnosis, up to a third (5 out of 13 or $38 \%$ ) developed neurological deterioration. ${ }^{4}$ Enhanced imaging protocols and a better understanding of these injuries has led to earlier diagnosis and treatment of these injuries with increasing rates of survival. However, with more timely diagnosis, earlier management, and improved care, patients with worse associated neurological injuries are also surviving at increasing rates. ${ }^{5}$ With better imaging and more severely injured patients surviving, we are now recognizing other associated injuries. Unstable subaxial fractures or fracture 
dislocations in association with CCD have yet to be reported.

The purpose of this study was to describe the "floating cervical spine" injury, defined as a CCD with an associated unstable, noncontiguous, subaxial spine fracture or dislocation. We sought to describe this injury pattern, assess its mechanism of injury, associated subaxial levels of injury and their morphology, associated neurovascular injuries, neurological status, survival, and surgical management to better understand these unique injuries.

\section{METHODS}

This study was reviewed and approved by the Institutional Review Board (IRB) of Harborview Medical Center, where this study was performed. After IRB approval, we conducted a retrospective study of all patients who sustained a CCD injury between January 1, 2003, and August 31, 2018. We identified patients from the prospectively collected trauma registry, billing registry and radiology records from a single level 1 trauma center. These were then cross-referenced with operative reports looking at International Classification of Diseases (ICD), Ninth Edition, codes $(805,806,839)$ or ICD10 codes (S12, S13, M53.2), Abbreviated Injury Scale (starting with 6402 and 6502), and Current Procedural Terminology codes (22950). Patients were included in this study if they sustained a CCD and a noncontiguous, unstable, subaxial fracture and/or dislocation which also was deemed operative.

A floating cervical spine injury was defined as a $\mathrm{CCD}$ in association with another unstable, noncontiguous, subaxial cervical or cervicothoracic spine injury. The term floating was chosen, as this is a term used to describe other musculoskeletal injuries such as a floating knee, described as an ipsilateral femur and tibia fracture, or floating elbow, described as an ipsilateral humerus and both-bone forearm fracture. CCD was defined as a dissociative injury sustained between the skull base and the second cervical vertebra. These included atlantoocciptal dislocations, atlantoaxial dislocations or a combination of both. More routine dens fractures, $\mathrm{C} 2$ pars fractures, or isolated $\mathrm{C} 1$ fractures were not included. An unstable subaxial cervical or cervicothoracic injury was defined as a 3-column injury that met criteria for surgical stabilization. Patients were included in this study if the subaxial spine injury occurred between the subaxial cervical and upper thoracic spine (C3-T2). T2 was chosen as the distal extent of the cervicothoracic junction. We included the upper thoracic levels because injury to this region would still result in an unstable floating cervical segment with the head cranially and the thorax distally being dissociated from the intervening cervical spine.

Demographic data, mechanism of injury, neurological status, vascular injury, type of treatment, follow up, and patient neurological outcomes were obtained from the electronical medical records. A detailed review of the imaging studies including computed tomography (CT) scans, magnetic resonance imaging scans, and CT angiograms was performed to collect spine injuries, localization, and type.

\section{Statistical Methods}

Data and descriptive analysis was performed using Excel (Microsoft Office Version 15). Data was reported as mean and standard deviation (SD). Given the small numbers and nature of this study, only descriptive statistics will be presented.

\section{RESULTS}

Overall, 117 patients with CCD were identified from the records. Twelve patients with known CCD died during initial workup in the emergency department before full spine radiographic workup and were excluded. A total of 105 patients with CCD had full spine radiographs, of which 13 patients $(12.4 \%)$ were identified as having an associated unstable subaxial injury between C3 and T2. Eight patients were male, and 5 were female with mean age of $45.4 \pm 19$ years. All patients were involved in high-energy trauma including motor vehicle collision ( 7 patients), pedestrian struck by car (3 patients), motorcycle collision (2 patients), and snowmobile collision (1 patient).

CCD was characterized in 4 patients as atlantooccipital dissociation (AOD), in 1 patient as atlantoaxial dissociation (AAD), and in 8 patients as a combination of both AOD and AAD injuries. The most common associated level was C6-C7, with 9 of the 13 subaxial cervical spine injuries occurring at this level. The most cranial associated level was C5-C6 (2 patients) and the remaining 2 occurring between $\mathrm{T} 1$ and $\mathrm{T} 2$ (Table 1). The presumed mechanism of injury as assessed by the injury CT 
Table 1. Patients demographics and injury characteristics.

\begin{tabular}{|c|c|c|c|c|c|c|}
\hline Case & Age & Sex & Mechanism of Injury & $\begin{array}{c}\text { Type of } \\
\text { Craniocervical } \\
\text { Injury }\end{array}$ & $\begin{array}{l}\text { Subaxial Spine } \\
\text { Injury Location }\end{array}$ & Subaxial Spine Injury Type \\
\hline 1 & 50 & $\mathrm{~F}$ & MVC & AOD & $\mathrm{C} 5-\mathrm{C} 6$ & Flexion distraction injury \\
\hline 2 & 43 & M & MVC & $\mathrm{AOD}+\mathrm{AAD}$ & $\mathrm{C} 5-\mathrm{C} 6$ & Extension distraction injury \\
\hline 3 & 63 & M & Snow mobile accident & AOD & $\mathrm{C} 6-\mathrm{C} 7$ & Extension distraction injury \\
\hline 4 & 25 & $\mathrm{~F}$ & Pedestrian struck by car & AOD & $\mathrm{C} 6-\mathrm{C} 7$ & Flexion distraction + unilateral jumped facet \\
\hline 5 & 20 & M & MVC & AOD & $\mathrm{C} 6-\mathrm{C} 7$ & Extension distraction injury \\
\hline 6 & 56 & M & Pedestrian struck by car & AAD & $\mathrm{C} 6-\mathrm{C} 7$ & Extension distraction injury \\
\hline 7 & 65 & M & $\mathrm{MCC}$ & $\mathrm{AOD}+\mathrm{AAD}$ & $\mathrm{C} 6-\mathrm{C} 7$ & Extension distraction injury \\
\hline 8 & 61 & $\mathrm{~F}$ & MVC & $\mathrm{AOD}+\mathrm{AAD}$ & $\mathrm{C} 6-\mathrm{C} 7$ & Distraction injury \\
\hline 9 & 9 & $\mathrm{~F}$ & MVC & $\mathrm{AOD}+\mathrm{AAD}$ & $\mathrm{C} 6-\mathrm{C} 7$ & Distraction injury \\
\hline 10 & 2 & $\mathrm{~F}$ & MVC & $\mathrm{AOD}+\mathrm{AAD}$ & $\mathrm{C} 6-\mathrm{C} 7$ & Distraction injury \\
\hline 11 & 62 & M & MVC & $\mathrm{AOD}+\mathrm{AAD}$ & $\mathrm{C} 6-\mathrm{C} 7-\mathrm{T} 1$ & Flexion distraction + bilateral facet dislocation \\
\hline 12 & 46 & M & $\mathrm{MCC}$ & $\mathrm{AOD}+\mathrm{AAD}$ & $\mathrm{T} 1-\mathrm{T} 2$ & Extension distraction injury \\
\hline 13 & 49 & M & Pedestrian struck by car & $\mathrm{AOD}+\mathrm{AAD}$ & $\mathrm{T} 1-\mathrm{T} 2$ & Flexion distraction + bilateral jumped facet \\
\hline
\end{tabular}

Abbreviations: AAD, atlantoaxial dissociation; AOD, atlantooccipital dissociation; MCC, motor circle collision; MOI, mechanism of injury; MVC, motor vehicular collision; Ped, pedestrian.

scans for the distal injuries consisted of a combination of extension and distraction (6), pure distraction (3), or a combination of flexion and distraction (4). Initial neurological examination was only obtained in 7 patients $(54 \%)$, with the remainder being unexaminable secondary to sedation and/or unable to participate in a focused exam because of severe closed head injuries or other significant associated injuries (Table 2). Of the 7 patients with baseline recorded neurological exams, 5 were American Spinal Injury Association (ASIA) A, 1 ASIA D, and 1 ASIA E. In the remaining 6 patients, no baseline neurological exam could be obtained until after their surgery.

Computed tomography angiogram (CTA) was obtained in 11 of the 13 patients; vascular injuries were reported in 7 patients $(54 \%), 5$ patients were shown to have a vertebral artery injury, 3 being at the level of the unstable injury of the subaxial cervical spine and 2 at the CCD (Table 2). The remainder of patients did not obtain CTA secondary to the patient's physiological stability issues, with 2 dying before completion of workup. Vascular injuries were treated after our hospital monitoring and management protocol. Patients with vertebral artery injury (any grade) and carotid injury (Biffl 1) underwent aspirin $325 \mathrm{mg} / \mathrm{d}$ for a total of 6 weeks if there were no contraindications. Patients with carotid injuries (Biffl 2-5) underwent transcranial Doppler (TCD) monitoring daily for 3 days for microemboli screening. Two patients received aspirin $325 \mathrm{mg}$, and 5 patients had contraindications to start this treatment. Only 2 patients were monitored with TCD, and both were negative for emboli.

Two patients $(15 \%)$ died in the emergency room or intensive care unit before undergoing operative

Table 2. Demographics of neurological status, vascular injury, and outcome disposition.

\begin{tabular}{|c|c|c|c|c|c|c|c|c|c|c|c|}
\hline \multirow[b]{2}{*}{ Case } & \multicolumn{3}{|c|}{ Initial Motor Exam } & \multicolumn{3}{|c|}{ Final Motor Exam } & \multicolumn{3}{|c|}{ Vascular Injury } & \multirow[b]{2}{*}{$\begin{array}{l}\text { Discharge } \\
\text { Disposition }\end{array}$} & \multirow[b]{2}{*}{ Outcomes } \\
\hline & Total & Level & Grade & Total & Level & Grade & Location & Segment & $\begin{array}{c}\text { Biffl } \\
\text { Classification }\end{array}$ & & \\
\hline 1 & 3 & C6 & A & 12 & C6 & A & VA & 2 & II & Rehab & \\
\hline 2 & 94 & NA & $\mathrm{D}$ & 94 & & $\mathrm{D}$ & $\begin{array}{l}\text { ICA } \\
\text { VA }\end{array}$ & $\begin{array}{c}\text { NA } \\
3\end{array}$ & $\begin{array}{l}\text { NA } \\
\text { I }\end{array}$ & Rehab & Home \\
\hline 3 & 2 & $\mathrm{C} 4$ & A & 4 & $\mathrm{C} 4$ & A & NA & NA & NA & Rehab & Home with caregiver \\
\hline 4 & NA & NA & NA & 64 & NA & $\mathrm{C}$ & NA & NA & NA & SNF & NA \\
\hline 5 & NA & NA & NA & NA & NA & NA & ICA & NA & I & Deceased & Severe TBI with clinical brain death \\
\hline 6 & NA & NA & NA & 90 & NA & $\mathrm{D}$ & NA & NA & NA & Care facility & Home \\
\hline 7 & 100 & NA & $\mathrm{E}$ & 100 & NA & $\mathrm{E}$ & VA & 3 & IV & Rehab & Home \\
\hline 8 & NA & NA & NA & 91 & NA & $\mathrm{D}$ & VA & 3 & I & Rehab & Home \\
\hline 9 & 0 & $\mathrm{Cl}$ & A & NA & NA & NA & NA & NA & NA & Deceased & Severe TBI with clinical brain death \\
\hline 10 & 0 & $\mathrm{C} 3$ & A & 0 & $\mathrm{C} 3$ & A & NA & NA & NA & Care facility & NA \\
\hline 11 & 0 & $\mathrm{C} 3$ & A & 13 & $\mathrm{C} 3$ & A & $\begin{array}{l}\text { ICA } \\
\text { VA }\end{array}$ & $\begin{array}{c}\text { NA } \\
2\end{array}$ & $\begin{array}{l}\text { II } \\
\text { I }\end{array}$ & Rehab & NA \\
\hline 12 & NA & NA & NA & NA & NA & NA & NA & NA & NA & Deceased & Multiorgan failure \\
\hline 13 & NA & NA & NA & NA & NA & NA & ICA & NA & II & Deceased & Severe TBI family directed comfort care \\
\hline
\end{tabular}

Abbreviations: ICA, internal carotid artery; NA, not available; Rehab, rehabilitation center; SNF, skilled nursing facility; TBI, traumatic brain injury; VA, vertebral artery. 
Table 3. Summary of surgical management and timing from onset of injury.

\begin{tabular}{|c|c|c|c|c|c|c|c|}
\hline Case & $\begin{array}{l}\text { Timing of Surgery } \\
\text { From Onset } \\
\text { of Injury, h }\end{array}$ & $\begin{array}{c}\text { No. } \\
\text { Surgeries }\end{array}$ & $\begin{array}{c}\text { CCD } \\
\text { Stabilized } \\
\text { First }\end{array}$ & $\begin{array}{c}\text { Levels of } \\
\text { Craniocervical } \\
\text { Fixation }\end{array}$ & $\begin{array}{c}\text { Type of } \\
\text { Fixation }\end{array}$ & $\begin{array}{l}\text { Levels of } \\
\text { Subaxial Spine } \\
\text { Fixation }\end{array}$ & Type of Fixation \\
\hline 1 & $<24$ & 2 & No & Occ-C2 & PSIF & $\mathrm{C} 5-\mathrm{C} 6$ & $\mathrm{ACDF}+\mathrm{PSIF}$ \\
\hline 2 & $24-48$ & 1 & Yes & Occ-C1 & PSIF & C5-C6 & PSIF \\
\hline 3 & $24-48$ & 2 & No & Occ-C2 & PSIF & $\mathrm{C} 6-\mathrm{C} 7$ & $\mathrm{ACDF}+\mathrm{PSIF}$ \\
\hline 4 & $<24$ & 1 & Yes & Occ-C2 & PSIF & C6-C7 & PSIF \\
\hline 6 & $<24$ & 2 & Yes & Occ-C2 & PSIF & C6-C7 & ACDF \\
\hline 7 & $<24$ & 1 & Yes & Occ-C2 & PSIF & C6-C7 & PSIF \\
\hline 8 & $>48$ & 1 & No & Occ-C2 & PSIF & $\mathrm{C} 6-\mathrm{C} 7$ & $\mathrm{ACDF}$ \\
\hline 10 & $<24$ & 1 & No & Occ-C2 & PSIF & C6-C7 & PSIF \\
\hline 11 & $24-48$ & 1 & Yes & Occ-T2 & PSIF & $\mathrm{C} 6-\mathrm{T} 2$ & PSIF \\
\hline 12 & $>48$ & 1 & Yes & Occ-C2 & PSIF & $\mathrm{T} 1-\mathrm{T} 2$ & PSIF \\
\hline 13 & $<24$ & 1 & No & Occ-C2 & PSIF & $\mathrm{T} 1-\mathrm{T} 2$ & PSIF \\
\hline
\end{tabular}

Abbreviations: ACDF, anterior cervical discectomy and fusion; Occ, occiput; PSIF, posterior spinal instrumentation and fusion.

management. Eleven patients underwent instrumented fixation of both the CCD and the subaxial injury. Short-segment posterior instrumentation and fusion was the selected surgical treatment for the secondary noncontiguous injury as well as for the occiput-C2 injury in 10 cases $(91 \%)$. In 8 patients, the instrumentation of the 2 noncontiguous injuries was performed in a single day. In 3 patients, their surgeries were done on 2 separate days due to baseline constitutional stability issues. In 5 cases, the distraction injury of the subaxial spine was fixed before the $\mathrm{CCD}$, based on the interpretation of the operating surgeon that the more caudal injury was more unstable than the CCD (Table 3).

Nine of the $13(69 \%)$ patients who arrived to the hospital alive survived to be discharged from the hospital. Of the 4 patients who died during their hospitalization, 2 patients died before undergoing any surgery (severe traumatic brain injury and brain death), and 2 patients died within 15 days of surgery (1 after family-directed withdrawal of care due to severe traumatic brain injury and 1 from multisystem organ failure). The 9 survivors had an average follow up of 2 years with a minimum of 9 months. Final neurological examination and patient outcomes are summarized in Table 2. Of the 9 survivors from the index 13 patients, 4 were ASIA A (C3, C3, C4, C6), 1 ASIA C (C6), 3 ASIA D, and 1 ASIA E, with only 4 patients $(44.4 \%$ of 9 survivors and $30.8 \%$ of the original 13 patients) living independently (ASIA D and E) at 2-year follow up.

\section{Illustrative Cases}

Below are 2 illustrative cases of the floating cervical spine injury. Both cases show the various presentations, treatment options, and outcomes that can occur in these injuries.

\section{Case 1}

A 50-year-old female was involved in a high-speed motor vehicle collision. Full spine CT showed an asymmetric widening of the right atlantooccipital joint with an apparently normal left joint and an associated C5-C6 significant distraction injury of 2 $\mathrm{cm}$ (Figures 1A and 1B). CTA identified a narrowing of $50 \%$ of the left vertebral artery (Biffl type 2) at C5-C6, consistent with arterial dissection or thrombus. Initial neurological examination demonstrated a complete spinal cord injury (ASIA A) at the C6 level. ${ }^{6}$ The patient underwent 2 surgeries on different days due to her metabolic instability. During the first stage, open reduction and C5-6 posterior segmentally instrumented arthrodesis was performed, followed by occiput-C2 posterior spinal instrumentation and fusion (Figure 2). A second stage anterior cervical discectomy and fusion (ACDF) of the C5-6 level was performed to achieve a $360^{\circ}$ fusion and improve stability. The patient was discharged to a rehabilitation facility with persistent ASIA A spinal cord injury but with an improved motor score from a baseline of 3 to 12 . Preoperatively, the patient only had $3 / 5$ biceps on the right and otherwise $0 / 5$ for all other motor groups. At final follow up, the patient had left $3 / 5$ biceps, $2 / 5$ triceps, $1 / 5$ wrist extension, and right $3 / 5$ biceps, $2 / 5$ triceps, and $1 / 5$ elbow extension with otherwise $0 / 5$ for other motor groups (Figure 3).

\section{Case 12}

A 49-year-old male was struck by a car and sustained multiple injuries, including bilateral carotid artery injuries, multiple rib fractures with associated lung parenchymal trauma, mediastinal hematoma, pelvic ring injury, and bilateral extremity fractures. Full spine CT showed right atlantooccipital and atlantoaxial joint widening and left 

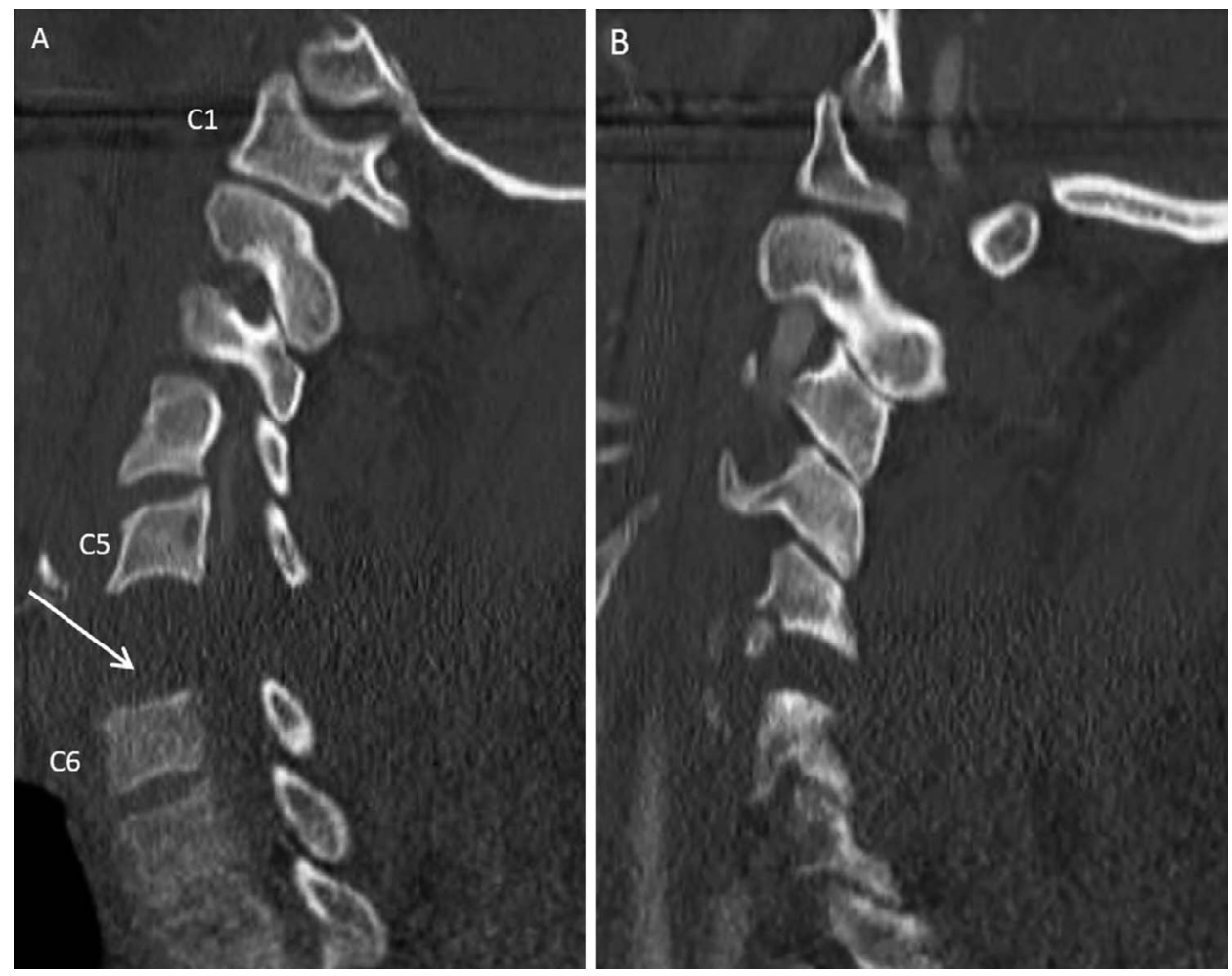

Figure 1. Cervical spine sagittal reformatted computed tomography scan showing (A) asymmetric widening of the right atlantooccipital joint (AOJ) space consistent with dissociation. Arrow shows significant distraction injury at C5-6 with approximately $2.0 \mathrm{~cm}$ in cranial caudal distraction. (B) Left AOJ with more subtle widening and subluxation as well.

atlantoaxial widening. There was an associated T1-

T2 flexion distraction injury with bilateral jumped

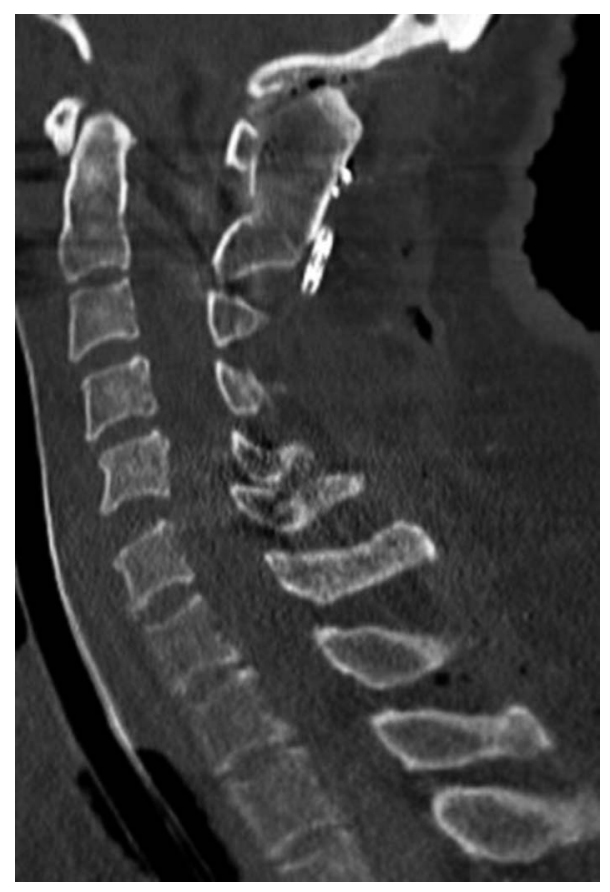

Figure 2. Postoperative (first stage) computed tomography image. Occiput-C2 posterior spinal instrumentation and fusion (PSIF) in near anatomic alignment and C5-C6 PSIF mild residual widening of the intervertebral space. facets (AO T1-T2 C injury with bilateral $\mathrm{F} 4$; Figures $4 \mathrm{~A}-4 \mathrm{C})$. CTA identified a narrowing of $40 \%$ of the left internal carotid artery (ICA; Biffl type 2) at $\mathrm{C} 2$ level consistent with arterial dissection or thrombus. Additionally, he was found to have a luminal irregularity with less than $25 \%$ of the right ICA adjacent to the lateral mass of $\mathrm{C} 1$ (Biffl 1). Initial neurological examination demonstrated a $\mathrm{T} 1$ complete spinal cord injury (ASIA A). The patient underwent open reduction and posterior segmentally instrumented fusion at $\mathrm{T} 1-\mathrm{T} 2$, followed by occiput-C2 posterior spinal instrumentation and fusion (PSIF). The patient died within 15 days after surgery due to a combined traumatic and ischemic brain injury (Figure 5).

\section{DISCUSSION}

$\mathrm{CCD}$ is an uncommon and frequently devastating injury, associated with high rates of morbidity and mortality. Advances in prehospital life support and immobilization on patients who have sustained high-energy trauma have resulted in an increase in the number of patients with CCD reaching the hospital. $^{1-3}$ Increased clinical suspicion and improvements in and standardization of spine imaging 


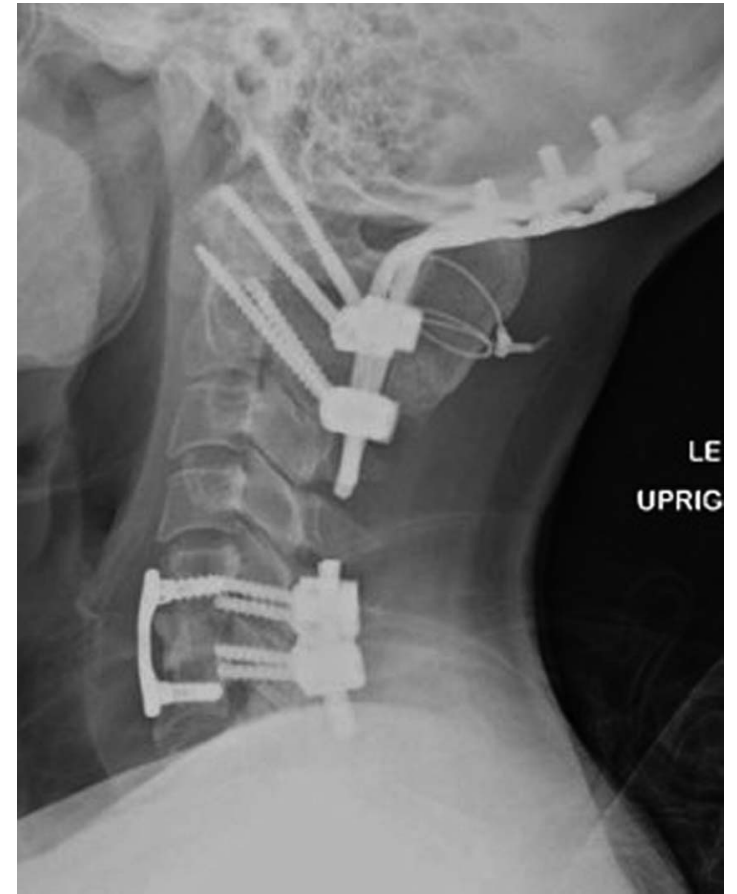

Figure 3. Postoperative x-ray lateral view (second stage) showing cervical anatomic alignment restored. Occiput-C2 posterior spinal instrumentation and fusion (PSIF) for the atlantooccipital dissociation. Interval C5-6 PSIF for the severe C5-6 distraction injury shows significant improvement in alignment.

protocols such as the inclusion of routine, fine-cut CT scan as part of the initial imaging modality has allowed for early, accurate diagnosis of spine injuries. $^{2,7}$
Current literature suggests a rate of noncontiguous fractures of the spine that ranges from $3 \%$ to $15 \% .^{8-10}$ Wittenburg et $\mathrm{l}^{11}$ identified a $3.7 \%$ incidence of unstable, noncontiguous spinal fractures in 1054 spine fracture patients over a 14-year period. Miller et $\mathrm{al}^{12}$ identified 40 patients $(8.1 \%)$ with an additional noncontiguous cervical spine fracture among 492 cervical spine fracture patients at their level 1 trauma center. The authors did not specify the morphology or stability of these secondary, noncontiguous fractures. Of note, they found significantly higher rates of cervical noncontiguous fractures in patients with occipital condyle, C2, C3, and C7 fractures. Between 2001 and 2006, Cooper et $\mathrm{al}^{1}$ identified 69 patients in King County that sustained CCD. Forty-seven of these patients were diagnosed postmortem by the King County Medical Examiner, while 22 were diagnosed at Harborview Medical Center. Additional spinal fractures were identified in 20 of the 69 patients $(29 \%)$, although the nature of these secondary injuries was not identified. In their series of 17 patients with CCD injuries, Bellabarba et $\mathrm{al}^{4}$ identified 2 patients with additional spine injuries, 1 in the lumbar spine and 1 in the subaxial cervical spine. Our series shows a $12 \%$ incidence of unstable, noncontiguous subaxial or cervicothoracic junction injuries in patients with CCD. These results, when viewed in conjunction
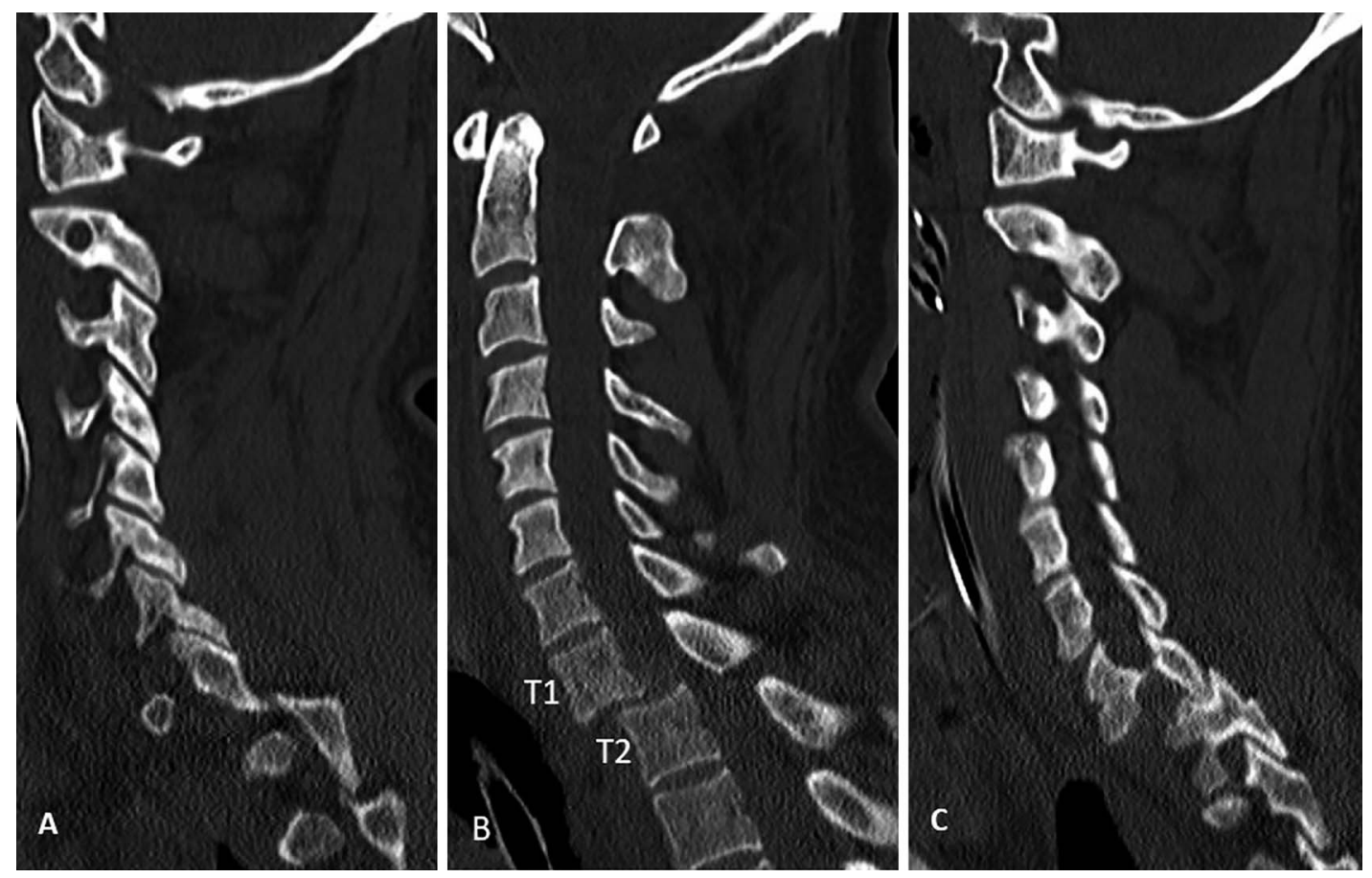

Figure 4. Cervical spine sagittal reformatted computed tomography scan showing (A) right occiput-C1 widening, right $\mathrm{C} 1-\mathrm{C} 2$ widening, and a dislocated right $\mathrm{T} 1-\mathrm{T} 2$ facet. (B) T1-T2 flexion distraction injury with bilateral jumped facets. (C) Left occiput-C1 with normal appearance but widening of C1-C2 and left T1-T2 dislocated facet. 


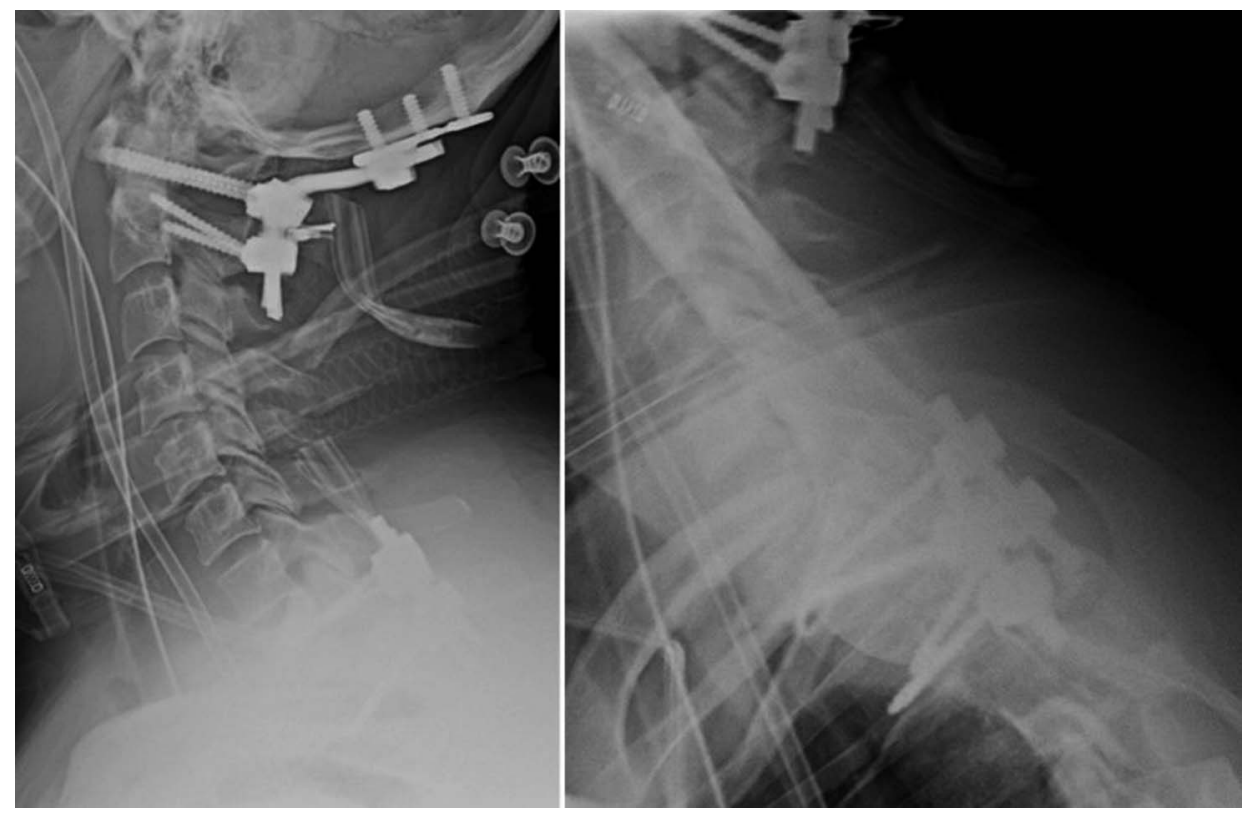

Figure 5. Postoperative x-ray (lateral view) demonstrating normal alignment after T1, T2 posterior spinal instrumentation and fusion (PSIF), and occiput-C2 PSIF.

with the findings of Cooper et $\mathrm{al}^{1}$ that $29 \%$ of CCDs have associated spine injuries, suggest that CCDs may be associated with a higher likelihood of noncontiguous spine injuries than other fracture patterns.

A delay in diagnosis of CCD has historically not been uncommon and has frequently been associated with preoperative neurological deterioration. Bellabarba et $\mathrm{al}^{4}$ identified 17 CCD survivors from 1996 to 2002 , with only $24 \%$ being diagnosed within the first 24 hours of admission. More importantly, 38\% of those with a delay in diagnosis had a profound neurological deterioration. The percentage of patients who were diagnosed early improved significantly in a follow-up study from the same institution, in which $74 \%$ of 31 new CCD survivors from 2003 to 2008 were diagnosed within the first 24 hours of admission and only 1 patient had a neurological decline because of a delay in diagnosis. ${ }^{5}$ They concluded that expedited diagnosis and early stabilization decreased the preoperative neurological deterioration. In the 13 patients presented in this study, only 11 survived long enough to undergo surgery, all of whom were fixed in an expeditious manner. Only 7 were examinable at baseline, and no patient had a known neurological deterioration, though only 2 of the 7 patients who had a documented baseline exam had the potential to worsen their ASIA grade since 1 patient was ASIA E, 1 was ASIA D, and the other 5 were ASIA A.
To our knowledge, this is the first time patients with floating cervical spine injuries have been described. We define the floating cervical spine injury as a pattern that involves a traumatic CCD (AOD and/or AAD) in association with a noncontiguous, unstable 3-column injury of the subaxial cervical (C3-C7) or upper thoracic (T1-T2) spine. We included the upper thoracic levels because injury to this region would still result in an unstable floating cervical segment with the head cranially and the thorax distally being dissociated from the intervening cervical spine. This allows for significant displacement in multiple planes, which increases the risk of repeat or worsening spinal cord or brainstem injury. An et $\mathrm{al}^{13}$ and Wang et al ${ }^{14}$ both commented on the special considerations of the cervicothoracic region, particularly the dynamic and static stresses across this segment as it transitions from the rigid and kyphotic thoracic spine to the mobile and lordotic cervical spine. Although the previous authors used T3 as the distal delineation, we believe our findings to be relatable, and for all intents and purposes, identical.

Studies show that neurologic injury can occur in up to $25 \%$ to $59 \%$ of patients with cervical spine fractures. ${ }^{15-17}$ By comparison, some studies have shown neurologic injury rates for patients with AOD that range from $58 \%$ to $100 \%$, with a particular association related to delay in diagnosis and thus a delay in management. ${ }^{3,4,18}$ Spinal cord injuries can vary in terms of severity with a large 
differential in function between a high cervical ASIA A and an ASIA D. Our study corroborates a high rate of neurological injury and a poor rate of recovery in patients with floating cervical spine injuries. Only 7 patients were examinable at presentation, and of the 7,5 were ASIA A with motor scores from 0 to 3,1 was ASIA D with a motor score of 94, and 1 was ASIA E. Of the 13 initial patients, 4 died before discharge, leaving 9 available for final assessment. Of the 9 , there were 4 ASIA A, 1 ASIA C, 3 ASIA D, and 1 ASIA E. Thus, of our starting cohort of 13 patients, only 4 $(31 \%)$ were able to live independently (ASIA D or E), and the other 5 survivors still required substantial support. This suggests a very poor prognosis neurologically for this type of injury. It also seems that the floating cervical spine injury generally has a worse neurological outcome than CCD alone, considering that, in the study by Bellabarba et al, ${ }^{4}$ the mean motor score at follow up was 79 , and the number of patients with useful motor function (ASIA Grade D or E) at follow up was $76 \%$.

The literature reports AOD and AAD mortality rates range from $22 \%$ to $82 \% .^{1,2,7,19-21}$ In contrast, Schellenberg et $\mathrm{al}^{21}$ noted that $78 \%$ of 1489 patients with unstable cervical injuries, identified from the National Trauma Data Bank between 2007 and 2014, survived through discharge. In our cohort of patients, in-hospital mortality rate was 34\% (4/13 patients). These patients died during the initial emergency department workup or within the first 2 weeks after their spine surgery, most of the time because of severe head injuries or multisystem organ failure. From the group of surviving patients that were discharged from the hospital, 3 patients were discharged to a rehabilitation facility, and 6 patients were discharged to home.

As a rule, the injury to the subaxial or cervicothoracic spine suggested a substantial amount of energy, given the degree of displacement. The 9 caudal injuries located in the subaxial spine were produced by a distractive type of force, like the type of force that causes most CCDs. Distractive injuries to the spine are unusual as isolated injuries. To sustain a 2-level distraction injury of the spine would likely require an inordinate amount of energy. The remaining 4 injuries were largely consistent with a flexion-distraction mechanism. These severe injuries to the bony and ligamentous components of the spine also create the potential for substantial injury to the spinal cord.
Of the 11 patients which underwent operative treatment, 10 had 2 separate fixation constructs. In 1 case, the patient had fixation from the occiput to T2. In terms of order of fixation, we could not identify any consensus, and as a rule, the more severely displaced injury was the first 1 addressed operatively. Surgery was usually done in an urgent manner to try to stabilize the spinal column and allow for early mobilization. With only $69 \%$ of patients ultimately surviving to discharge and $31 \%$ of patients being able to live independently, it is important to discuss with family members and powers of attorney the implications and expectations associated with this injury.

Certainly, there are limitations to this study. This was a retrospective, observational study of only 13 patients with 9 survivors. Certainly, there also could have been more injuries in the surrounding area that never made it to the hospital alive as well. Because patients generally arrived to the hospital intubated and unexaminable, our ability to gain baseline information, particularly neurological status, was quite limited. Forty-six percent of our patients did not have a reliable neurologic exam documented on admission due to the severity of their injuries. This is a limitation but also an indication of the severity of the injury. Many of the patients without a full exam had blunt head injuries, intracranial injuries, and multiple extremity injuries. The combination of a small number of patients and lack of established protocol in the management of these patients, with treatment varying among different spine surgeons, limited our ability to draw treatment-related conclusions or provide treatment guidelines. Ultimately, some conclusions can be made, but there is more to be learned from these patients with floating cervical spine injuries.

\section{CONCLUSIONS}

In our series, approximately $12 \%$ of the patients with a CCD had an associated, unstable cervical or cervicothoracic injury. These are clearly very highenergy injuries with a guarded prognosis, and family members and powers of attorney should be counseled as to expectations. Floating cervical spine injuries result from high-energy mechanisms with only $69 \%$ surviving to hospital discharge and only $31 \%$ living and functioning independently (ASIA D or E). These are potentially devastating injuries, as out data suggest, with high mortality and disability; however, we must recognize these patterns and 
manage them expeditiously to allow for a functional prognosis for those who have the potential to survive and may function independently.

\section{REFERENCES}

1. Cooper Z, Gross JA, Lacey JM, Traven N, Mirza SK, Arbabi S. Identifying survivors with traumatic craniocervical dissociation: a retrospective study. J Surg Res. 2010;160(1):3-8. doi:10.1016/j.jss.2009.04.004

2. Horn EM, Feiz-Erfan I, Lekovic GP, Dickman CA, Sonntag VK, Theodore N. Survivors of occipitoatlantal dislocation injuries: imaging and clinical correlates. J Neurosurg Spine. 2007;6(2):113-120. doi:10.3171/spi.2007.6.2.113

3. Mendenhall SK, Sivaganesan A, Mistry A, Sivasubramaniam P, McGirt MJ, Devin CJ. Traumatic atlantooccipital dislocation: comprehensive assessment of mortality, neurologic improvement, and patient-reported outcomes at a level 1 trauma center over 15 years. Spine J. 2015;15(11):2385-2395. doi:10.1016/j.spinee.2015.07.003

4. Bellabarba C, Mirza SK, West GA, et al. Diagnosis and treatment of craniocervical dislocation in a series of 17 consecutive survivors during an 8-year period. J Neurosurg Spine. 2006;4(6):429-440. doi:10.3171/spi.2006.4.6.429

5. Reis A, Bransford R, Penoyar T, Chapman JR, Bellabarba C. Diagnosis and treatment of craniocervical dissociation in 48 consecutive survivors. Evid Based Spine Care J. 2010;1(2):69-70. doi:10.1055/s-0028-1100920

6. Biffl WL, Moore EE, Offner PJ, Brega KE, Franciose RJ, Burch JM. Blunt carotid arterial injuries: implications of a new grading scale. J Trauma. 1999;47(5):845-853. doi:10.1097/ 00005373-199911000-00004

7. Kasliwal MK, Fontes RB, Traynelis VC. Occipitocervical dissociation-incidence, evaluation, and treatment. Curr Rev Musculoskelet Med. 2016;9(3):247-254. doi:10.1007/s12178016-9347-6

8. Cho SK, Lenke LG, Hanson D. Traumatic noncontiguous double fracture-dislocation of the lumbosacral spine. Spine J. 2006;6(5):534-538. doi:10.1016/j.spinee.2006.01.015

9. Iencean SM. Double noncontiguous cervical spinal injuries. Acta Neurochir (Wien). 2002;144(7):695-701. doi:10. 1007/s00701-002-0940-7

10. Pellise F, Bago J, Villanueva C. Double-level spinal injury resulting in "en bloc" dislocation of the lumbar spine. A case report. Acta Orthop Belg. 1992;58(3):349-352.

11. Wittenberg RH, Hargus S, Steffen R, Muhr G, Botel U. Noncontiguous unstable spine fractures. Spine (Phila Pa 1976). 2002;27(3):254-257. doi:10.1097/00007632-200202010-00010

12. Miller CP, Brubacher JW, Biswas D, Lawrence BD, Whang PG, Grauer JN. The incidence of noncontiguous spinal fractures and other traumatic injuries associated with cervical spine fractures: a 10-year experience at an academic medical center. Spine (Phila Pa 1976). 2011;36(19):1532-1540. doi:10. 1097/BRS.0b013e3181f550a6

13. An HS, Vaccaro A, Cotler JM, Lin S. Spinal disorders at the cervicothoracic junction. Spine (Phila $P a$ 1976). 1994;19(22):2557-2564. doi:10.1097/00007632-19941100100011
14. Wang VY, Chou D. The cervicothoracic junction. Neurosurg Clin N Am. 2007;18(2):365-371. doi:10.1016/j.nec. 2007.02.012

15. Gao W, Wang B, Hao D, et al. Surgical treatment of lower cervical fracture-dislocation with spinal cord injuries by anterior approach: 5- to 15-year follow-up. World Neurosurg. 2018;115:e137-e145. doi:10.1016/j.wneu.2018.03.213

16. Kano H, Matsuo Y, Kubo N, Fujimi S, Nishii T. Spinal injuries in suicidal jumpers. Spine (Phila $P a$ 1976). 2019;44(1):E13-E8. doi:10.1097/BRS.0000000000002757

17. Lomoschitz FM, Blackmore CC, Mirza SK, Mann FA. Cervical spine injuries in patients 65 years old and older: epidemiologic analysis regarding the effects of age and injury mechanism on distribution, type, and stability of injuries. AJR Am J Roentgenol. 2002;178(3):573-577. doi:10.2214/ajr.178.3. 1780573

18. Chaput CD, Torres E, Davis M, Song J, Rahm M. Survival of atlanto-occipital dissociation correlates with atlanto-occipital distraction, injury severity score, and neurologic status. J Trauma. 2011;71(2):393-395. doi:10.1097/TA 0b013e3181eb6a31

19. Filiberto DM, Sharpe JP, Croce MA, Fabian TC, Magnotti LJ. Traumatic atlanto-occipital dissociation: no longer a death sentence. Surgery. 2018;164(3):500-503. doi:10. 1016/j.surg.2018.05.011

20. Imaizumi $T$, Sohma $T$, Hotta $H$, Teto I, Imaizumi $H$, Kaneko M. Associated injuries and mechanism of atlantooccipital dislocation caused by trauma. Neurol Med Chir (Tokyo). 1995;35(6):385-391. doi:10.2176/nmc.35.385

21. Schellenberg M, Inaba K, Cheng V, et al. Independent predictors of survival after traumatic atlanto-occipital dissociation. J Trauma Acute Care Surg. 2018;85(2):375-379. doi:10. 1097/TA.0000000000001953

Disclosures and COI: No benefits in any form have been or will be received from a commercial party related directly or indirectly to the subject of this paper. Author RJB reports outside the submitted work personal fees from Globus and AO Spine for speaking and teaching arrangements and grants from AO Spine for fellowship support. For the remaining authors, none are declared.

Corresponding Author: Richard J. Bransford, MD, Department of Orthopaedics and Sports Medicine, Harborview Medical Center, 325 Ninth Ave, Seattle, WA 98104. Phone: (206) 744-3466; Fax: (206) 744-4407; Email: rbransfo@uw.edu.

Published 0 Month 2021

This manuscript is generously published free of charge by ISASS, the International Society for the Advancement of Spine Surgery. Copyright (C) 2021 ISASS. To see more or order reprints or permissions, see http://ijssurgery.com. 